\title{
GESTIONANDO DISTANCIAS Y DISPUTANDO SABERES EN EL HOGAR: EMPLEADAS Y EMPLEADORAS DEL SERVICIO DOMÉSTICO EN BUENOS
} AIRES

\author{
Santiago Canevaro ${ }^{1}$
}

\section{Introducción}

La cotidianeidad del trabajo doméstico remunerado que realizan empleadas en los hogares de sus empleadores de Buenos Aires supone una situación laboral ambigua, al estar atravesada por relaciones afectivas, que no son puramente contractuales, donde la reciprocidad y el intercambio tornan aún más complejo el tipo de vínculo en dicho espacio. La particularidad se aloja en que el lugar donde la empleada doméstica desarrolla su actividad laboral es, al mismo tiempo, el ámbito doméstico, de privacidad e intimidad de una familia que no es la propia. Esta doble condición del espacio (de trabajo para unas y de intimidad para otros) constituye el tamiz por el cual se moldean los tipos de relaciones sociales y modos particulares de vinculación laboral.

La propuesta de este artículo es indagar en el universo de acuerdos, negociaciones y disputas entre empleadas domésticas y empleadoras del servicio doméstico cuando se pone en juego la organización de las tareas de limpieza y de cuidados de niños dentro del hogar. En tal sentido, nos centraremos en la forma que adquiere la gestión ${ }^{2}$ y organización del trabajo, analizando la dinámica de conflictos, disputas y arreglos que surgen entre ambas en torno a las 'maneras de hacer' (De Certeau, 1996) el trabajo doméstico así como respecto a la administración del tiempo y de los espacios compartidos.

Más allá de la diversidad de situaciones laborales y de actividades agrupadas en la categoría de servicio doméstico, los estudios cualitativos elaborados en diferentes países de la región revelan que las asalariadas del sector se encuentran entre las categorías más desfavorecidas en términos de condiciones de trabajo y de vida. De la misma manera,

\footnotetext{
${ }^{1}$ Universidad Nacional de San Martín, Argentina.

${ }^{2}$ Aunque la palabra puede tener una connotación o más bien derivarse de las teorías modernas del manejo de personal, considero que la misma tiene una amplitud conceptual al involucrar aspectos vinculados con la dirección, el control, la organización y la toma de decisiones. En este sentido, la noción de gestión supone relaciones de poder en tanto que la capacidad de administrar se deriva de las posibilidades que tienen los agentes sociales para organizar, disponer y administrar conocimientos y recursos, en este caso, dentro de un hogar. No se trata de suponer que en la esfera doméstica se generan relaciones similares a las que se dan en una relación laboral "clásica" sino, más bien, hacer el ejercicio de pensar cómo algunas herramientas pueden funcionar en diferentes espacios.
} 
estos estudios ponen de manifiesto la complejidad de la relación que se establece entre empleadas y empleadores del servicio doméstico. En efecto, esta relación laboral, al involucrar actores que se encuentran en situaciones sociales y económicas profundamente desiguales, combina proximidad física y distancia social.

En tal sentido, consideramos importante reconocer, siguiendo a Jurema Brites (2001), que las distancias sociales entre clases sociales en Argentina no deben ser solamente visualizadas a través del estudio de los contrastes en relación a los consumos materiales de cada una, sino que también pueden ser las lógicas culturales aquello que le otorga a los grupos sociales alejamientos significativos. ${ }^{3}$ De allí que la realidad para cada grupo se represente por experiencias y concepciones distintas que imponen particularidades en término de las prácticas y saberes en relación a, por ejemplo, la organización familiar, las concepciones políticas y religiosas, la concepción sobre la salud, el cuidado, el dolor, la limpieza, la infancia, etc. ${ }^{4}$

Encontramos que el espacio de interacción como setting privilegiado lo constituye el hogar de la empleadora y será allí donde se produzcan los cruces e interacciones en términos dinámicos de códigos y lógicas culturales. Sin embargo, los objetivos de ambas son distintos ya que por un lado, las empleadoras tienen como objetivo principal poder lograr que el trabajo sea realizado de una manera similar a como lo harían ellas mismas y en ese camino, movilizan capacidades y estrategias que utilizan con esta finalidad; mientras que por el otro, las empleadas domésticas tienen que obedecer las órdenes de las empleadoras, aunque siempre actuando desde sus propios saberes y conocimientos sobre "cómo" hacer las tareas domésticas y de cuidado de niños.

Pero no todas las empleadoras ni las empleadas domésticas son iguales. Así, se ha optado por diferenciar entre dos tipos de empleadoras -aquellas que están más tiempo fuera del hogar y aquellas que permanecen en el hogar durante el día- y dos tipos de empleadas domésticas, considerando la modalidad de trabajo - sea "con retiro" o "sin retiro"- con el fin de complejizar el análisis de la forma en la que se organiza la relación laboral.

\footnotetext{
${ }^{3}$ En Brasil, una extensa y rica literatura existe al respecto. Claudia Fonseca (1995) en su estudio sobre las concepciones de familia en los sectores medios y populares de Porto Alegre, así como Luiz Fernando Días Duarte (1986), en su clásico estudio sobre los "nervios" en los sectores populares, constituyen esfuerzos en esta línea.

${ }^{4}$ Ello no significa que los sectores populares tengan una vida aislada sino que más bien, es en las propias experiencias y vivencias, donde los patrones de cultura dominante son reelaborados, aceptados o cuestionados por estos grupos desde la lógica cotidiana. De allí que tampoco se pueda hablar de una homogeneidad de los grupos populares, debiendo hacer mención a la heterogeneidad de los mismos (Grignon y Passeron, 1991).
} 
En el caso de las empleadoras, es posible identificar que, independientemente de su condición de actividad ${ }^{5}$, en su mayoría guardan expectativas acerca de los procedimientos y modos de realizar el trabajo doméstico. Sin embargo, advertiremos cómo la presencia y/o ausencia de la empleadora en el hogar incide en los niveles de tolerancia y umbrales de limpieza que las empleadoras pueden maniobrar, llevando a la generación de arreglos diferenciales en función de las posibilidades y la importancia que los empleadores le otorguen a ciertas cualidades de las empleadas.

En este sentido, el punto de partida es pensar que los desacuerdos y conflictos que se producen entre ambas partes sobrevienen de concepciones diferentes en relación con el significado y la "forma" de limpiar y ordenar una casa, así como a los procedimientos y medios que deben ser utilizados para cuidar a un niño. ${ }^{6}$ Esta búsqueda de cierta similitud en la forma de ejecución de las tareas de limpieza y de cuidado de los niños serán entendidas como `maneras de hacer’ (De Certeau, 1996).

Al mismo tiempo, veremos los límites "morales" que estas empleadoras manifiestan cuando son trascendidas ciertas fronteras. De allí que los métodos de persuasión y de gestión del vínculo laboral con la empleada guarde características singulares, siendo las situaciones inconfortables e incómodas instancias donde se condensa y expresa la variabilidad de resoluciones adoptadas.

Por su parte, las empleadas saben que deben aceptar un conjunto de instrucciones y disposiciones mínimas sobre el trabajo que deben realizar, aunque muchas de ellas perciben que cada hogar guarda su propia particularidad, rasgo y matiz que es necesario conocer y respetar, y que puede ir desde cómo tender una cama hasta el planchado de una camisa, pasando por la mejor manera de limpiar los baños con determinados

\footnotetext{
${ }^{5}$ Éste recorte resulta aún más significativo si tomamos en cuenta el contexto socio histórico que busca retratar este artículo. Así, en los años noventa en Argentina se profundizó un proceso que venía consolidándose desde fines de los años setenta, como es el masivo ingreso de las mujeres de sectores medios al mercado laboral formal (Informe del Ministerio de Trabajo de la Nación, 2005). Esta entrada masiva, sumada a una ausencia de una política pública de guarderías y de atención de los niños, hizo que en los años noventa se decaduplicara según cifras extra oficiales la contratación de empleadas para la realización de tareas domésticas y de cuidado de niños. Dicho carácter masivo modificó al mismo tiempo las prácticas y características del control laboral y directivas ligadas a las labores domésticas. El ingreso de la mujer al mercado laboral y a sus propios requerimientos y obligaciones provocó una consecuente disminución de los métodos y formas de control y regulación de las tareas realizadas por las empleadas. De allí que pudimos encontrar, sobre todo entre aquellas empleadoras que trabajan, una disminución en la práctica ligada a la supervisión y el control de las tareas dentro del lugar de trabajo.

${ }^{6}$ Esta información comenzó a surgir de mis primeras incursiones en el trabajo campo. A los lamentos que ya configuraban en mi experiencia de vida un rosario variopinto de cuestiones, se le agregaron diversas quejas ligadas a la limpieza, el orden, las mentiras, insolencias, "faltazos" e intolerables "hurtos" y "robos" que en general los empleadores atribuían a sus empleadas.
} 
productos, la ubicación de los juguetes de los niños, el lugar donde deben ser extendidos los trapos que ya están limpios, hasta cómo y de qué manera comunicarse con los niños.

En general, independientemente del trabajo que realicen, las empleadas desean recibir de la manera más precisa y clara posible aquellas instrucciones que les permitan saber qué tienen que hacer manteniendo la autonomía acerca de cómo hacer las tareas. De allí que veremos en algunos casos cómo, para mejorar la calidad y cantidad de trabajos, algunas empleadas prefieren contar con horarios flexibles, otras prefieren generar relaciones de mayor intimidad y confianza con los empleadores, mientras que otras optan por mantener una mayor distancia con éstos.

La modalidad de trabajo actúa como un contorno que define la medida y la capacidad que tienen las empleadas tanto para maniobrar su autonomía dentro del trabajo como la relación que establecen con las empleadoras dentro del hogar. Así, la modalidad de trabajo interviene en las opciones y posibilidades que tengan las empleadas para negociar sus horarios así como para poder establecer arreglos laborales que puedan favorecerlas. De este modo, en el caso de las empleadas "sin retiro", la dificultad para poder regular la temporalidad dentro del trabajo así como el compromiso emocional que se forja usualmente con los hijos de sus empleadores generan conflictos de distinta naturaleza y carácter de aquellos que pueden darse con las empleadas "con retiro". Estas últimas tienen otra forma de organizar sus itinerarios laborales y buscarán para poder hacerlos factibles lograr una mayor autonomía y libertad para administrar sus horarios de entrada y salida. Al mismo tiempo, son quienes deben conocer en mayor medida los matices y detalles acerca de la forma de ejecución del trabajo en cada uno de los hogares donde se desempeñan.

La particularidad del caso reside en que, más allá de que las empleadoras puedan brindar las indicaciones e instrucciones de un modo preciso, tanto la concepción que guía la práctica $^{7}$ así como la separación que se produce con la empleadora, llevan a que finalmente las empleadas realicen sus labores desde sus propios conocimientos e ideas.

\footnotetext{
7 Bourdieu y Passeron (1971) consideran que a través de la transmisión del saber, se inculcan ciertas predisposiciones a percibir, sentir, valorar, pensar y actuar en la realidad, que se inscriben en el cuerpo de los sujetos y se instala de una manera duradera y exhaustiva, más o menos naturalizada. Utilizando el mismo ejemplo que para el caso de la socialización utilizan los autores, podríamos pensar que la "socialización doméstica" consiste en la transmisión e internalización de un conjunto de convenciones que se inscriben como parte del "sentido práctico" y que vuelven significativos, razonables, legítimos, aceptables, los mandatos morales, los modos correctos de limpiar y de ordenar, y el reconocimiento de ciertos enunciados como verdaderos.
} 
Esta distancia permite a la empleada la utilización de "tácticas"8 en contraposición a las "estrategias" "que implementan las empleadoras - ambos conceptos tomados desde el sentido otorgado por De Certeau (1996). La empleada moviliza un conjunto de acciones que, realizadas de manera insinuada, en un juego de aparición y de sombras, nos permiten develar aquellos rasgos invisibles del arte espontáneo, que en tanto actos $a d-h o c$, son difíciles de capturar y de percibir, pues son establecidos en los pliegues de la propia dominación. Pero como veremos, esta posibilidad de desbordar los límites de la sujeción tendrá sus propios límites y márgenes que nos posibilitarán inmiscuirnos en la creatividad cotidiana de las empleadas que - elusiva, dispersa, fugitiva, hasta silenciosa, fragmentaria y artesanalmente- se las arreglan para construir sus propias "maneras de hacer" y sus propias formas de transitar y negociar su presencia en ese espacio (De Certeau, 1996). ${ }^{10}$

Teniendo todos estos elementos en cuenta, veremos en un primer momento cómo las empleadoras utilizan diversas estrategias para lograr que las empleadas se acerquen lo más posible a sus expectativas y aspiraciones en relación con la organización de lo doméstico. Así, los esfuerzos irán desde el control del tiempo, las tareas, el registro y la vigilancia, hasta la evaluación del "producto" y los gestos maternales adecuados para con los hijos, como prácticas tendientes a lograr tales objetivos. Así, consideramos que la condición de actividad entre las empleadoras constituye un recorte relevante a la hora de analizar tanto las estrategias como las limitaciones y posibilidades de gestionar, negociar y tramitar la dinámica organizativa del trabajo doméstico.

En un segundo momento, para el caso de las empleadas, tomamos como significativa la modalidad de trabajo de que se trate -"sin retiro" y "con retiro"-, en tanto

\footnotetext{
${ }^{8}$ De Certeau la entiende como una "acción calculada que determina la ausencia de un lugar propio. Por tanto ninguna delimitación de la exterioridad le proporciona una condición de autonomía. La táctica no tiene más lugar que el del otro. Además debe actuar con el terreno que le impone y organiza la ley de una fuerza extraña [...] es movimiento "en el interior del campo de visión del enemigo" [...] No cuenta con la posibilidad de darse un proyecto global ni de totalizar al adversario en un espacio distinto, visible y capaz de hacerse objetivo" (De Certeau, 1996: 43).

${ }^{9}$ En sus palabras, De Certeau la comprende como aquel "cálculo (o manipulación) de las relaciones de fuerzas que se hace posible desde que un sujeto de voluntad y de poder (una empresa, un ejército, una ciudad, una institución científica) resulta aislable. La estrategia postula un lugar susceptible de circunscribirse como algo propio y de ser la base donde administrar las relaciones con una exterioridad de metas o de amenazas" (De Certeau, 1996: 42).

${ }^{10}$ Ya no se trata (sólo) de pensar en la productividad del poder, del ejercicio del poder; sino en la productividad de las micro-resistencias movilizadas a partir de las prácticas cotidianas; porque "no hay prácticas sin uso", por eso De Certeau habla de practicantes y no de consumidores (De Certeau, 1996). Para un excelente análisis sobre la forma en que los grupos subalternos inventan tácticas para minimizar las desventajas y hasta poder obtener algún provecho del sistema, se recomienda el estudio de James Scott (1985).
} 
factor que nos permite revelar tanto la diversidad de arreglos y gestiones que se establecen con las empleadoras que se relacionan con las tareas, los tiempos, instrucciones, exigencias e implicancias afectivas que se pongan en juego, realizando posteriormente algunas consideraciones finales.

\section{Empleadoras}

\subsection{Empleadoras que no están en los hogares}

Para estas empleadoras, la elección de contratar a una persona tiempo completo en la semana supone que puedan hacerse cargo de las distintas tareas domésticas, liberándolas de la responsabilidad de tener que observar no sólo si el trabajo se realiza sino también de pensar en el mismo. Aunque puedan darles algunas indicaciones verbales o reprenderlas solamente cuando encuentran que el trabajo realizado no se ajusta a sus expectativas, en una gran cantidad de casos, sus itinerarios laborales no les permiten tener el tiempo necesario para poder tener contactos extensos con las empleadas.

Sin embargo, y aún las que menos están en el hogar y sostienen que les interesa poco el "tema de la casa", manifiestan quejas en torno al desconocimiento o a la "falta de criterio" que encuentran entre las empleadas domésticas cuando se trata de realizar las tareas domésticas ligadas a la limpieza y al cuidado de niños. Por este motivo, reconocen que las empleadas que se acercan más a tales criterios son aquellas que mayores posibilidades tienen de continuar en el trabajo. En este sentido, son tanto esta capacidad de manejar un razonamiento similar al de las empleadoras así como la habilidad de reconocer rápidamente las necesidades esenciales para el sostenimiento del hogar aquellos rasgos de similar importancia en una empleada

Poder "adelantarse" y leer aquellas necesidades y estados de ánimo constituyen cualidades que se vuelven esenciales en la vida cotidiana de estas empleadoras. El carácter resolutivo y la capacidad de iniciativa emergen para estas empleadoras como características importantes dentro de su modelo, en el cual cuanto menor y más efectiva es la interacción con la empleada, mayor es el beneficio para ellas

Por un lado, encontramos aquellas empleadoras que permanecen todo el día fuera de la casa y que, aunque son renuentes a controlar a sus empleadas, guardan altas expectativas de calidad y cantidad en el trabajo realizado. Milagros, de cuarenta y dos años, casada, empleada administrativa, con dos hijos y que trabaja más de diez horas 
por día, considera a la empleada que trabaja en su hogar como "cualquier trabajadora, que quiere hacer su trabajo bien, rápido y de forma eficiente, entonces yo qué les voy a explicar, les digo, esto es lo que tienen que limpiar, es lo mínimo de limpieza que pido y me voy, pero que lo cuiden a los chicos bien, sobre todo".

Sin embargo, en una de las entrevistas con Milagros, reconocerá la generación de un conflicto a partir de la actitud de una empleada que había trabajado en la casa de su madre por más de diez años. Milagros reconoce en "Luz [empleada doméstica], una manera de trabajar que nunca vi, súper pulcra, ordenada”. Si bien en los primeros tiempos para ella la presencia de Luz había sido fundamental debido a su ausencia por trabajo durante semanas, posteriormente su presencia comenzó a generarle dificultades: "es que la verdad que ordenaba demasiado, era muy detallista (...) y sobre todo con mis hijos porque se creía con la libertad de hacer lo que quisiera cuando yo volví’. Milagros comenzó a pensar en despedirla aunque se aseguró de conseguirle trabajo en la casa de una amiga suya. Esto lo hizo por recomendación de su propia madre, quien le dijo que lo mejor era siempre tener a la empleada de "buen humor" sobre todo si uno estaba por cambiarla y no estaba mucho en la casa para ver qué hacía con sus hijos. Aunque fue difícil la salida de Luz porque según Milagros "estaba también muy encariñada con los chicos", la nueva empleada (Griselda) que ingresó en su reemplazo era mucho menor de edad y de experiencia como empleada doméstica.

Con el antecedente del conflicto muy cercano, Milagros decidió llamar a su madre para que fuera quien se ocupara de brindarle algunas indicaciones respecto al trabajo que debía realizar. Milagros reconoce que prontamente encontró en el trabajo de Griselda una tranquilidad:

Me di cuenta que me gustaba que me ordenen, pero no "tanto" (...) pero más me pasó con los chicos porque esta chica ya no se tomó las atribuciones de Luz, que me hacía pasar una factura, digamos, porque yo no estaba y ella cuidaba de mis hijos mientras dejaba a los suyos en su casa. Esto lo pensé tiempo después.

En términos generales, podríamos interpretar que estas empleadoras, profesionales, con una reducida presencia en sus hogares, esperan que las tareas estén resueltas cuando retornan a sus hogares después de una jornada laboral para, de este modo, no tener que destinar tiempo a la misma ni a la propia gestión que supone el vínculo con la empleada. Asimismo, maniobran una compleja articulación entre proximidad (sobre todo cuando están implicadas tareas de cuidado) y de distancia (cuando deben establecer prioridades y ubicarse en el lugar de patronas). 
Finalmente, una mayor autonomía de estas empleadas puede ser leída por las empleadoras como un comportamiento que puede terminar entorpeciendo sus propios itinerarios profesionales y familiares, con lo cual deben combinar en la propia gestión cotidiana una relación de proximidad para lograr una comunicación precisa con un alejamiento necesario para brindar dar órdenes de manera efectiva.

\subsection{Límites culturales y limitaciones morales}

El hecho de tener pocas oportunidades físico-temporales para brindar las recomendaciones y realizar una supervisión exhaustiva no implica que estas empleadoras dejen las cosas libradas al azar, sino que se preocupan por brindar aunque sea mínimas instrucciones y orientaciones específicas sobre cuestiones domésticas que consideran esenciales, como pueden ser la limpieza de los baños, cuartos y hornos así como los productos requeridos para el cuidado de los niños. Entre algunas empleadoras encontramos muy extendido el sistema de cuadernos y notas donde dejan instrucciones precisas, mientras que otras tratan de regresar antes de que las empleadas dejen el hogar para controlar la realización de las tareas. En general, hemos encontrado empleadoras que manifestaron intenciones voluntad de contar con el tiempo necesario para poder controlar las distintas etapas del trabajo, aunque sus agendas laborales y múltiples compromisos son lo que no las dejan en condiciones de poder realizarlo. En este sentido, cierto umbral de limpieza y cierto temor por el manejo de códigos y prácticas distintas ligadas al cuidado de los niños que aparece en los relatos de estas empleadoras debe ajustarse cotidianamente a uno de los mayores temores que significa poder quedarse instantáneamente sin empleada doméstica. En tal sentido, y ante la situación que puede derivar en la pérdida de una empleada, muchas empleadoras manifestaron obviar ciertas críticas y consideraciones que harían en otras circunstancias, con tal de garantizar la continuidad de la empleada.

Sin embargo, y a pesar de la importancia que reviste contar con una empleada de confianza para estas empleadoras, muchas de ellas admitieron que los compromisos y obligaciones profesionales las llevaron muchas veces a dejar "a cargo" a una empleada de la casa y de sus hijos sin brindarles mucha información al respecto. De esta manera, muchas de estas empleadoras que trabajan todo el día son también las que aceptan lo 
injusto y poco realista que es suponer que las empleadas telepáticamente puedan reconocer lo que ellas están esperando.

En definitiva, al estar mucho menos tiempo en sus hogares, las empleadoras que trabajan indefectiblemente otorgan mayor autonomía a las empleadas. Norma, de cuarenta y seis años, profesora de nivel terciario como Mirta, de cincuenta y un años, asistente en una escuela para personas con discapacidad, siempre que tuvieron empleada manifestaron "por lo bajo" el disgusto que tenían acerca de la manera en que sus hogares eran limpiados o la forma cómo cuidaban a sus hijos. Consideran que por sus profesiones y obligaciones, la tranquilidad de tener a una persona de confianza a quien pudieran transmitir sus requerimientos, era siempre la pauta que terminaba primando. Otras empleadoras reconocieron la imposibilidad que tenían de poder criticar a una persona que además de no ver durante el día, terminaba teniendo un rol similar al de ellas. Por ello, la identificación que siente Elizabeth con su empleada en tanto "trabajadora como yo" y el reconocimiento acerca del rol que ocupa en el hogar, apareció de diversas maneras en varios relatos de estas empleadoras:

Es que tienen el control y eso es un hecho, vos no estás en todo el día y no podes saber (...) Aparte, yo no nací para ser la patrona como me dicen ellas a veces, Yo les digo que también soy empleada y no me gusta andar criticándolas, la verdad que no. (...)

A pesar de la incomodidad que surge en sus relatos, esta identificación no las exime de poder ejercer ciertas observaciones y vigilancias sobre el trabajo que realiza la empleada, aunque son distintas a las que podíamos/podríamos/podemos encontrar mayoritariamente entre las empleadoras que están más tiempo en el hogar: "Uso maneras menos invasivas, viste, por ejemplo, ¿vio como quedó el piso de la salita de estar después de la lluvia?, qué raro, ¿no?” (Elizabeth). De esta manera, las formas de ejercicio de autoridad solapadas constituyen un canal de expresión que permite hacer la supervisión si necesidad de caer en el autoritarismo.

Otras empleadoras como Marta, cincuenta y dos años, tres hijos, casada y maestra, directamente manifiestan incomodidad cuando tienen que pronunciar órdenes e instrucciones. En el caso de Marta, como una ex militante peronista que luchó décadas atrás por los derechos igualitarios de las distintas clases sociales, se reconoce perteneciente a una generación con una conciencia social y solidaria hacia los sectores populares. Haber militado en barrios populares durante los años setenta y haber formado parte de una agrupación de mujeres de sectores populares que reivindicaban y luchaban 
por modificar la posición social subordinada que les tocaba vivir, hicieron que Marta sienta dificultades para mostrarse como la "patrona":

Imagináte que las consignas eran "abajo los patrones", "fuera la oligarquía" y todo eso, y ahora otra posición social en la escala social y que ahora sos vos la patrona, me siento muy hipócrita ahora. Temo que un día me hagan el planteo que yo hacía en su momento.

Admite que al margen de que no creía en la jerarquía entre ambas también consideraba necesario en muchos momentos poner ciertos límites. Su trabajo como docente y su participación en algunos negocios inmobiliarios junto a su marido hacían que le resultase imposible examinar cuidadosamente las tareas realizadas por la empleada.

Al mismo tiempo, es en este grupo de empleadoras donde encontramos un alto grado de incomodidad en los momentos que comparten con las empleadas cuando por algún motivo deciden quedarse en la casa. Resultaron interesantes algunos relatos de empleadoras que se quedan eventualmente desempleadas, siendo una práctica común la de no quedarse cerca de las empleadas cuando éstas realizan su trabajo en sus hogares. Muchas de ellas mencionan la necesidad imperiosa de estar fuera de la casa mientras aquellas realizan su trabajo. Algunas arreglan salidas, encuentros, trámites, mientras que otras salen a tomar un café, o van a la plaza con sus hijos cuando la empleada llega.

Aquellas empleadoras que deciden quedarse en el hogar, al hacerlo tratan de mantener el menor contacto posible con la empleada, siendo ese contacto una intromisión que vislumbran perjudicial para la actividad de la empleada. Dentro de este grupo, algunas mencionan sentirse culpables por la presencia de personas de menores recursos económicos limpiando sus casas, otras sienten ser entrometidas en el trabajo de las empleadas si se quedan en sus hogares, mientras que un tercer grupo siente la presencia de las empleadas como una intromisión a su privacidad y, por ende, tratan de modificar los horarios y formas de trabajo de la empleada para su mayor comodidad.

Aunque en términos generales podemos expresar que las empleadoras que trabajan fuera de sus hogares manejan un discurso comprensivo sobre la situación de la empleada, muchas mencionaron en varias oportunidades las limitaciones que encontraban para que las empleadas logren comprender las órdenes que ellas brindan.

La referencia a cierta "brutalidad" y falta de "delicadeza" en la forma y el uso que le daba a los instrumentos de limpieza y a las maneras de cuidar a sus hijos llevaron por ejemplo a Irma (52, separada, contadora, 3 hijos) a considerar a una empleada que tuvo 
más de cinco años como una “(...)persona de las cavernas, un yetty (...) no sabes como la levantaba por el aire a mi nena que tendría un añito y medio, le hacía como un juego que para mí le iba a terminar quebrando los bracitos".

Al mismo tiempo, la empleada retratada por Graciela tenía la "capacidad de romper todo lo que tocaba, entonces no podías comprar nada muy sofisticado porque no sé como hacía pero lo destruía". Graciela reconocía una disposición cultural de varias de sus empleadas, "sobre todo las del interior profundo", afirmando que su actitud ante estas situaciones había sido de comprensión de la situación ya que más allá de que "cuidaban muy bien a mis chicos, yo me daba cuenta que no era mala voluntad, sino al contrario, querían limpiar bien pero no podían, y bueno, mientras no fueran un desastre total yo no tenía otra".

Finalmente, uno de los temas donde mayores complicaciones aparecían era el momento en que la empleada se retiraba de la casa. Al estar ausentes cuando las empleadas salen del hogar, muchas empleadoras que trabajan manifestaron preferir estar presentes cuando éstas se retiran. Aunque Marisa, empleadora de treinta y seis años, médica y madre de cuatro hijos, reconoce que le tiene mucha confianza a su empleada y que tiene la llave de su casa, reflexiona cómo siendo que ella le paga "por el trabajo", y no por la cantidad de horas que trabaja, muchas veces ha percibido que la empleada se había retirado antes del horario convenido, porque "las cosas que le pedí no estaban hechas como yo le pedí". 11

Otras empleadoras, como Julia, profesora de inglés, casada y con dos hijos, reconoce haber tenido varios problemas con "dejar a la chica sola" porque "al dejarla sin control sobre lo que hacía y a qué hora se iba, tampoco sabía bien porque no hacía lo que yo quería”. Julia relata la experiencia que le tocó vivir a su marido, que un día que llegó tres horas antes del trabajo descubrió que la empleada se había retirado. Cuando Julia describe el hecho lo hace mostrando una gran desazón porque una empleada que ella considerada su "preferida" le había mentido. Esta situación le generó la incomodidad de tener que incorporar alguna estrategia que le permitiera controlar de alguna manera el trabajo que realizaba su empleada. Así fue como implementó un sistema como el de realizar llamadas media hora antes de que finalizara el horario

\footnotetext{
${ }^{11}$ Este tipo de arreglos sólo puede darse cuando la empleada realiza tareas de limpieza. Podríamos decir que cuando las empleadas domésticas logran establecer este tipo de acuerdos es cuando mayor confianza en relación a la forma de realizar el trabajo tiene la empleadora sobre la empleada. Bajo este sistema es Mary Romero plantea que las empleadas domésticas pueden posicionarse como "profesionales" que venden un tipo de servicio en el mismo sentido que lo puede hacer una vendedora de productos que lo hace hacia distintos compradores (Romero, 1992).
} 
laboral de su empleada, que aunque reconoce como "medio policial", le terminó funcionando. También reconoce que sus amigas y parientes le comentaron de otras formas utilizadas para el mismo objetivo, como pedirle a las propias empleadas que las llamen a sus trabajos o celulares cuando terminan o consultar al portero, vecino y/o al canillita de la esquina sobre los horarios de salida.

\subsection{Las empleadoras que están en sus hogares: eficacia y autoridad}

En términos generales, estas empleadoras se encuentran más tiempo en el hogar y establecen una supervisión y una vigilancia más fina y puntillosa sobre las tareas que realizan las empleadas domésticas. A diferencia de las empleadoras que tienen dificultades para ejercer la autoridad en tanto "patronas", el hecho de estar presentes mientras las empleadas desarrollan sus tareas no constituye un obstáculo para establecer una posición de mando. Es más, estas mujeres no tienen problemas en llevar a cabo una observación puntillosa y detallada de las tareas, horarios y maneras como las empleadas desarrollan sus actividades. Este hecho las lleva a que, indefectiblemente, tengan que establecer una mayor interacción con las empleadas, lo cual redunda en que deban constantemente lidiar con las "distancias personales y sociales" a las que hace referencia Edward Hall (1986: 139). Este rol las lleva a dar constantemente directivas y orientaciones precisas sobre las mejores "maneras de hacer" (De Certeau, 1996) el trabajo.

En tal sentido, Sonia (cuarenta y nueve años, separada, tres hijos, vive sola), una empleadora que contrató a una empleada doméstica "con retiro" para que trabaje en su enorme casa declaraba:"Es importante que ellas sepan lo que vos querés, cómo lo querés, y eso solamente lo logras diciéndole cómo te gustan que hagan las cosas". Para Sonia, "inculcarle lo que quiero es lo más importante, por eso no puedo pensar que ella va a saber cómo yo quiero las cosas si no le muestro". ${ }^{12}$

La tarea de brindar el ejemplo desde la propia destreza para luego supervisar que la ejecución se haga de la manera más cercana a la pauta brindada constituye un quehacer que para muchas amas de casa mejora su posición, transformando el rol que

\footnotetext{
12 A diferencia del "control taylorista" que muestra Hondagneu Sotelo (2001) en su estudio sobre empleadoras amas de casa, en nuestro caso apareció claramente explicitada la cuestión del "ejemplo directo", sin necesidad de mediación alguna como pueden ser las listas o inventarios detallados sobre las tareas específicas.
} 
podría ser visualizado como pasivo y aislado en uno activo y con autoridad (Romero, 1992: 84).

La misma Sonia reconoce en ese sentido:

Es como que le tenés que mostrar que en esta casa mando yo, porque esas chicas, si conocen lo hacen como ellas quieren porque piensan que una no sabe, es primeriza, y te pasan por encima.

Sonia, al igual que otras empleadoras, reconoce que en la actualidad, las empleadas "están más avivadas" y que deben tomar precauciones en cuanto a las "libertades" que se otorgan y las formas de control que se utilizan. Dentro de esta línea de reflexión, trazan una diferencia con las empleadas de antaño ${ }^{13}$, quienes desde su perspectiva, manejarían un comportamiento distinto al de las empleadas en la actualidad.

En este sentido, uno de los mayores temores entre las empleadoras que permanecen más tiempo en los hogares es la existencia de empleadas que logren una autonomía tal que no puedan ser controladas. Varias de estas empleadoras hicieron referencia a estas empleadas con personalidades "enérgicas" y "manipuladoras", "confianzudas" y "desubicadas", como aquel grupo que se debe combatir cuando se detecta su germen. Josefina, una empleadora de unos sesenta años, casada hace cuarenta y ama de casa hace treinta, con una casa muy grande en una zona de altos ingreso de la ciudad, relata cómo había tenido que pedir a una empleada (Yolanda) que "se moderara" porque, según su criterio, "se había creído la dueña de la casa y que estábamos a sus ordenes nosotros y no ella”. Recordando aquella experiencia que, según su relato, "marcó a toda la familia, porque todos la sufrimos", hacía referencia al aprendizaje y a los objetivos que tiene cuando busca una empleada: "Yo siempre digo que tienen que poder ayudarme y responder a las cosas que yo les pido, pero no que le das la mano, y después te toman el tiempo". Esta sensación manifestada por Josefina y presente en varios relatos de estas empleadoras, nos recuerda a De Certeau (1996) con su concepción de la estrategia como un cálculo de las relaciones de fuerza, cálculo (un tipo de racionalización) de aislar un lugar que se hace propio para sí. Se trata, parafraseando a este autor, de poder capturar algo que se considera como propio para poder controlarlo.

\footnotetext{
${ }^{13}$ Cierta idealización de las empleadas consideradas "como las de antes" emerge en varios de los relatos con las amas de casa, asociando en sus prácticas y hábitos más comunes el de saber mantener las distancias, sin perder la posibilidad de generar relaciones de confianza con las empleadoras.
} 
Beatriz, 52 años, casada y con dos hijos, tiene una mirada más realista sobre el tema y considera haber aprendido con los años que "uno le puede decir todo lo que quiera pero ellas terminan haciendo lo que quieren". Este reconocimiento de Beatriz de la utilización de tácticas por parte de las empleadas para actuar dentro de un terreno que no les es propio y que se les impone, no estaba exento de ciertas astucias que había desarrollado. Su estrategia desde hace cinco años consiste en mostrarles durante las primeras semanas la forma de hacer el trabajo y el resultado esperado, para después controlarlas cotidianamente. Sin embargo, la parte del control cotidiano constituye una tarea que para Beatriz no trae en general los resultados esperados. Por lo tanto, y al igual que muchas de estas empleadoras, la consigna es decirle a la empleada que "lo haga como ella quiere", pero sin dejar de lado "lo que yo quiero que haga". 14

La complicación que puede traer este tipo de negociaciones y apropiaciones diferenciales de las pautas y criterios informados son conflictos y tensiones de distinto orden, que buscan disipar de diferentes maneras. Una de las más conocidas es hablar con otra ama de casa que se transforma en referente sobre el "manejo del personal", y en quien confían sus dificultades y las maneras de resolver los conflictos que puedan surgir. Josefina representa dicho ejemplo, ya que es quien además de estar casada hace veintinueve años, ser madre de cuatro hijos y nunca haber trabajado, es reconocida por sus amigas como alguien que tiene una facilidad excepcional para comunicarse con sus empleadas y un referente para recurrir cuando alguna situación confusa se presenta y es quien asesora a sus amigas acerca de cómo dar directivas a sus empleadas. ${ }^{15}$

Habiendo trabajado más de quince años "ayudando" a su marido en el manejo del personal de una empresa de venta de servicios informáticos para empresas, Josefina reconoce que fue más en mi "experiencia en la casa, con el 'personal', los chicos y esas cosas, que me hice ducha", alegando que "no es gran cosa lo que hago, el tema es que viene Patricia [empleadora] y me dice, que tiene tal problema, entonces yo le digo 'pero si vos siempre me decís que Sara es muy buena, ¿se lo dijiste?’”. El problema según la

\footnotetext{
${ }^{14}$ En este punto, es interesante seguir la propuesta de Paula Abal Medina (2007) cuando criticando la noción de resistencia que De Certeau toma en cuenta cómo las estrategias del poder supone también una operación de captura de aquellas "maneras de hacer" que implican usos inesperados, inadecuados y/o sorpresivos no se entiende. En tal sentido, cuando Josefina admite que para lograr el resultado esperado por parte de las empleadas la estrategia es que utilicen sus propias "maneras de hacer", busca incorporar esos saberes sin dejar de reproducir la asimetría en la relación de fuerzas.(2007: 07)

15 "A la casa de Adriana llegué recomendado por otras empleadoras -también amas de casa-, quienes mencionaron el conocimiento y experiencia que tiene Adriana en el "tema del servicio". Además de notar un trato bastante ameno con las dos empleadas que la acompañaban también noté una distancia que era respetada por ambas partes".
} 
experiencia de Josefina es que "nos cuesta agradecer, tenemos una cultura de criticar mucho, aparte que no nos gusta hacer ese trabajo (...) Yo les digo que no es tan importante la cantidad de cosas que uno le diga sino el cómo". ${ }^{16}$ Continuando con su explicación Josefina enfatiza en que

Para estas mujeres [empleadas] hacer ese trabajo también puede ser denigrante, pero es su trabajo y hay que agradecerlo como si fuera cualquier otro trabajo, o reconocerlas cuando hacen algo que nos encanta, que un regalito, que una palmadita o una frase del tipo 'muchas gracias' cuando hacen algo que nos gusta ayuda a que el equilibrio se mantenga.

Mientras que en el caso de Josefina vemos cómo la diplomacia y la comprensión de las posiciones y roles de cada una es una cuestión central para resolver los conflictos, muchas otras empleadoras pasan la mayor parte del tiempo en el hogar y no tienen problemas a la hora de inspeccionar el trabajo que realizan las empleadas. Vilma, una mujer sin hijos que actualmente está jubilada y es esposa de un escribano, reconoce:

Yo no puedo estar sentada leyendo un libro o moviéndome de pieza en pieza. Si estoy en la casa quiero decirle que haga las cosas como a mí y a mi familia nos gusta (...)Es también mi rol como patrona, vigilar que todo se haga bien, como una fábrica, donde las cosas que no se hacen bien se tiran a la basura y las que se hacen bien quedan así.

Asimismo, Vilma reconoce una forma que encontró para poder "vigilarla a la chica", pero sin molestarla: "me pongo a la par y cuando veo algo que no está bien hecho, lo hago deshacer junto con ella y le muestro cómo me gusta a mí que se haga”.

Como vimos, para estas empleadoras, tanto la habilidad como cierta competencia en las labores domésticas son elementos que son puestos en juego en la interacción con la empleada doméstica. Si por un lado se reconoce que el "saber hacer" y la "manera de hacer" son distintas entre una y otra, queda en la competencia del empleadoras que están en el hogar poder mostrar y lograr el resultado esperado tanto sea desde arreglos más consensuados como por intermedio de una disciplina más inflexible y rigurosa con la empleada.

\footnotetext{
${ }^{16}$ En uno de los manuales más difundidos sobre el tema en Argentina y dirigidos a las empleadoras que deben tratar con las empleadas domésticas se hace referencia a estos puntos en un capítulo que se titula: "Corrija sin Retar". Allí se detalla la manera más precisa para tratar con la empleada: "Dirijo, no mando: ésta es la premisa principal. Lidero mi casa y a mis empleados, ese es el secreto. Si tengo que marcar alguna falta debo hacerlo desde la autoridad y el llamado de atención debe ser hecho con docencia, que tenga como fin la modificación de la conducta errónea del trabajador y ello se logra haciéndole ver con claridad donde está la equivocación y cuál es la solución para no repetirlo" (De las Casas y De las Casas, 2007: 68).
} 
De esta manera, si hasta el momento hemos analizado la importancia que ocupa la presencia de las empleadoras en el hogar durante la jornada laboral de la empleada, tanto en relación con la organización del trabajo como en las posibilidades de comunicar órdenes, negociar tareas y establecer acuerdos en función de sus propias necesidades y expectativas, a continuación exhibiremos las experiencias, sentidos y estrategias que movilizan las empleadas domésticas en las distintas labores que realizan desde las distintas modalidades de trabajo.

\section{Las empleadas}

\subsection{El trabajo "sin retiro"}

En general, los cronogramas y necesidades de los empleadores hacen que los servicios provistos por las empleadas domésticas que trabajan bajo esta modalidad comiencen bien temprano en la mañana y finalicen a altas horas de la noche. A esta disponibilidad temporal para realizar las tareas domésticas le debemos agregar, en la mayoría de los casos, el cuidado de niños, jóvenes o ancianos, tareas que vuelven más complicado el poder dejarse horas libres.

Una dificultad bastante frecuente para las empleadas que cuidan niños es que se les exige como parte del trabajo tener que dormir en los cuartos de los hijos de sus empleadores. ${ }^{17}$ María, que trabajó durante más de cuatro años cuando recién llegó desde Mar del Plata en la casa de una familia que tenían una hija de cuatro años, recuerda que por los problemas respiratorios de la menor de edad habían decidido que ella durmiera en el cuarto de la hija del matrimonio; algo que terminó transformando su trabajo en un sufrimiento. Muchas empleadas mencionan que estas situaciones en las cuales al mismo tiempo que pueden ser despertadas durante la noche las priva de tener sus propios cuartos donde dormir, resultan traumáticas y cansadoras. El retraimiento a la habitación particular de cada empleada aparece en muchos relatos como una forma de resistencia y de cuestionamiento de la ampliación del horario laboral.

Habida cuenta de este tipo de arreglos, la posibilidad de poder limitar la cantidad de horas a doce por día, se constituye para muchas empleadas "sin retiro" en uno de sus

\footnotetext{
${ }^{17}$ La dimensión de los hogares de sectores medios de Buenos Aires no permite la presencia de "cuartos de servicio" o de ambientes extras destinados a la habitación de la empleada doméstica. Ello hace que en su mayoría deban compartir ambientes con los niños que cuidan. Ello, además, garantiza una mayor cercanía con quienes cuidan y una mayor seguridad para los empleadores. Lo que deriva en su mayoría en un aumento exponencial del trabajo de las empleadas y una desaparición de propio espacio de intimidad.
} 
mayores logros. Muchas empleadas que tienen este tipo de trabajos manifestaron dificultades al respecto, como Rosa, que trabajó más de ocho años en una casa cuidando a tres chicos y limpiando: "Hacía todo, mientras la tenía a la beba en brazos y la hago dormir seco la ropa, y al mismo tiempo lavo los platos, y así te vas arreglando". Algunas otras, como Gladis, que trabaja desde hace seis años con una familia de psicoanalistas con dos hijos de la zona de Palermo, veían con gratitud cómo después del primer año donde ella se sentía un "pulpo" por la cantidad de cosas que tenía que hacer, pudo negociar un descanso de tres horas por la tarde. Aunque Gladis continúa con este nuevo arreglo alcanzado trabajando más de once horas por día, considera que "en la situación actual, esto es un avance para mí", porque anteriormente "no tenía descanso casi, dormía cuatro horas", aunque reconoce que "siempre igualmente termino trabajando lo mismo porque lo que te dan por acá, después te lo quitan, y es así."

Esta resignación que muestra Gladis sería, parafraseando nuevamente a De Certeau (1999), una cualidad de la táctica que maniobran las propias empleadas domésticas. En tal sentido, la táctica tiene la capacidad de ser al mismo tiempo una acción directa en estado puro que aprovechando las ocasiones, los subterfugios del poder, logra "golpear". Sin embargo, al depender de esas ocasiones, no puede acumular sus beneficios. "No guarda lo que gana". La táctica es ausencia de poder, pero es acción, procedimiento válido porque acusa y/o refiere al tiempo, tratando de usarlo de la manera más hábil y allí donde el poder muestra sacudidas.

En este punto, nos interesa mostrar las formas que encuentran las empleadas para organizar su propia temporalidad dentro del trabajo. Cuando una empleada está en un hogar cinco o seis veces por semana, elabora rutinas que incluyen lavar los lunes, pasar la aspiradora los martes, planchar los miércoles y así sucesivamente, tal vez dejando otras tareas para cuando los niños están durmiendo la siesta, o antes de regresar a casa desde la escuela por la tarde. Asimismo, esta organización del tiempo en el espacio se asocia con las características y dinámicas específicas de cada hogar. La presencia o no de la empleadora resulta un elemento central para pensar la manera en que se utiliza este tiempo "libre" o "muerto" para éstas empleadas. Así, encontramos que las empleadoras que ya tienen a sus hijos más grandes consideran que las empleadas cuando están "sin retiro" y ya no deben afrontar el cuidado de niños menores de edad, son, por ende, las responsables por buscar y reconocer otras actividades que justifiquen las horas de trabajo. 
Por su parte, las empleadas reconocen que cuando crecen los niños que estaban cuidado ellas comienzan a ser observadas como personas con "tiempo de sobra", por lo que se vuelve imprescindible, como destaca Teresa (empleada "sin retiro" durante más de ocho años),

Iinventarte cosas nuevas para hacer sino querés terminar haciendo cosas que no te gustan (...) A mí me mandaban a la casa de la suegra, ayudarla a ella, y después volvía y otra notita, que cambiar los cueritos, o los foquitos, limpiar el vidrio dos veces por semana, entonces me inventaba cosas porque yo eso no iba a hacer.

Así, estas empleadas sienten la sobrecarga de nuevas tareas y muchas veces más esforzadas ${ }^{18}$ que las anteriores sin que tampoco ello se derive en un aumento de sus honorarios o en un mayor reconocimiento. Por otra parte, muchas empleadas consideran que "hacerse tiempo libre" dentro del trabajo "con cama" puede constituirse en un arma de doble filo, en el sentido de que en un primer momento la velocidad, versatilidad y destreza pueden ser considerados elementos positivos y de reconocimiento de los empleadores, aunque al poco tiempo pueden convertirse en fuentes de mayor explotación para la empleada, al darle derecho a los empleadores para agregar otras tareas y responsabilidades.

Rosario (cuarenta y dos años, casada, dos hijos, tres años como empleada "sin retiro") comenta cómo al principio para ella significaba un orgullo mostrar su velocidad para las tareas que le encomendaban. Luego comenzó a notar que se cansaba mucho y que estaba todo el día haciendo distintas cosas: "es que siempre en una casa y más si es grande, tenés cosas para hacer y estás todo el día, más”. Esta sobrecarga de trabajo se resolvió cuando ella decidió comenzar a manejar su tiempo en el trabajo. Así, cuenta como "a diferencia de cuando trabajas en casa por horas, ahí tenés todo el día para hacer el trabajo y si haces todo a la mañana y a la tarde terminas, después te llama la patrona o el patrón y te pregunta si terminaste, o vienen, y ahí nomás te dan otra cosa porque te ven que tenés todo el día".

A diferencia de Graciela, Etelvina comentaba cómo era su “(...) propia forma de ser, con hormigas en el culo, como se dice" lo que le impedía trabajar menos tiempo y poder organizar su temporalidad dentro del trabajo. Etelvina recuerda que tal era la exigencia que ella misma se autoimponía que llegó un día en que se desmayó en la

\footnotetext{
${ }^{18}$ Limpiar bauleras, cambiar alacenas de lugar, cortar el césped o ayudar en la realización de alguna actividad comercial de la familia son algunas de las tareas extra para las empleadas que siguiendo como "sin retiro" ya no tienen que cuidar de los niños de la familia.
} 
cocina. Sin embargo, en las diversas conversaciones que tuvimos con Etelvina logramos encontrar otros elementos que nos permiten complejizar el hecho.

Todos los días salvo los domingos, durante más de ocho años, Etelvina se levantaba a las cinco y media de la mañana y luego de bañarse, sacaba a pasear a los dos perros de la familia y comenzaba a levantar a los niños de la casa, preparándoles el desayuno antes de que a las siete y veinte pasara el micro para buscarlos. Fue durante los meses en que sus dos empleadores (una pareja de abogados) estuvieron trabajando en la propia casa que Etelvina se sintió sobrecargada de trabajo. La permanencia casi constante de estas personas agregó más trabajo al habitual ya que debía cocinar y realizar tareas extras. Desde llevarle té a su empleador hasta estar atenta de no molestar a su empleadora cuando trabajaba o llegaban visitas, cuidar que los perros no entraran a la casa y modificar hábitos para no molestarlos, como no escuchar la radio en la cocina, no cantar o no poder hablar tranquila con su hermana por teléfono, cuestiones que transformaron su cotidianeidad, haciéndola estar más pendiente de las tareas domésticas. Cocinar todos los días -tanto al mediodía como a la noche- para seis personas, luego estar atenta por la tarde de las necesidades y gustos de ambos empleadores una vez que los niños volvían del colegio, hicieron de ese período uno de los más difíciles y cansadores. Así fue como tuvo un desmayo en la cocina que derivó en dos semanas de reposo para ella.

Etelvina explica que fue por su propia tendencia a no querer negarse a realizar todas las tareas que le requerían de la manera correcta y sobre todo al "cariño" que ella sentía por los dos niños que cuidaba que accedió a realizar tareas que la terminaron sobrecargando y llevando en algunas oportunidades hasta el desmayo. Cuando se la consulta por esa experiencia afirma de manera reflexiva que su capacidad, su edad y el reconocimiento que sentía por parte de sus empleadores, fueron elementos que la hacían sentirse orgullosa. En sus palabras: "Imaginate, que yo era una chica sola, que venía del campo y ahora estaba llevando adelante yo sola una casa enorme". Etelvina destaca que no eran "tanto mis patrones" los que la exigían en las tareas domésticas sino que era más bien ella, quien "estaba todo el día haciendo cosas, que una torta, que cosiendo, haciendo pulóveres, cosas para los chicos, que ni me pedían pero que yo hacía, que se yo...porque estaba cómoda, me sentía como en mi casa”. Es interesante lo que agrega la historia de Etelvina a las anteriores empleadas "sin retiro", en relación con el entrecruzamiento de la dinámica afectiva y subjetiva en la forma en la que se organiza el trabajo doméstico de una empleada "sin retiro". 


\subsection{El trabajo "con retiro" 19}

A diferencia de las empleadas que duermen en los hogares de los empleadores, quienes trabajan semanalmente (ya sea de una a cuatro veces por semana), establecen, negocian y generan relaciones sociales diferentes de las empleadas "sin retiro". Por un lado, y a pesar de las negociaciones que como vimos implica la organización de la domesticidad, la realización de tareas que supongan únicamente tareas de limpieza en un hogar ya constituye una labor donde hay menos carga emocional y, por lo tanto, hay una menor probabilidad de que se generen discrepancias que las existentes cuando se debe combinar la tarea de limpieza con el de cuidado de niños. Sin embargo, un elemento central en este tipo de trabajo lo constituye el hecho de que es mayormente corriente que las interacciones cara a cara entre empleadas y empleadores sean menos frecuentes o breves en el tiempo.

En general, las empleadas que tienen varias casas ingresan al hogar donde trabajan con las mismas llaves, limpian en soledad y toman su salario diario, viendo esporádicamente a sus empleadores. Otras empleadas realizan la limpieza en presencia de algún empleador aunque incluso en estos casos suelen encontrarlos una vez por semana o dos veces por mes, pero nunca diariamente. Finalmente, y a diferencia de aquellas que trabajan "sin retiro", las empleadas que realizan tareas de limpieza tienen distintos tipos de empleadores, pudiendo limpiar una o dos casas en días distintos y hasta posiblemente manteniendo otros trabajos de tiempo parcial en los días que tienen libres. Por consiguiente, una empleada que limpia y que está consolidada en su trabajo es aquella que teniendo una multiplicidad de "casas" corre poco riesgo si es que pierde un trabajo que resulta problemático para continuar en el rubro. ${ }^{20}$ La consolidación en el rubro igualmente lleva su tiempo y tiene diversas temporalidades en función de la confianza y las garantías que pueden ir obteniendo en cada una de las casas. Como veremos a continuación, cuanto mayor sea la confianza que logren, menores serán las

\footnotetext{
${ }^{19}$ Por motivos de espacio, sólo consideramos para este artículo a las empleadas "con retiro" incluyendo en esta categoría a quienes trabajan y/pero no pernoctan en los hogares de sus empleadores y trabajan sin la presencia de niños. Reconociendo que el trabajo con retiro semanal constituye un "intermedio" desde el trabajo "sin retiro" al trabajo "por horas", quisimos enfatizar las diferencias entre ambos para esta presentación. Asimismo, focalizarnos en los casos de empleadas que solamente desarrollan tareas de limpieza nos permite indagar con mayor profundidad en las propias estrategias y prácticas culturales que desarrollan para conseguir, mantener y mejorar sus condiciones laborales.

${ }^{20}$ Este punto reafirma una constante en relación a las diferenciaciones que se producen en términos de las condiciones salariales y de trabajo de las empleadas, al no tener tanto que ver con el corte "con retiro" o "sin retiro" sino con la cantidad de empleadores con los que cuentan cada una.
} 
observaciones y controles que puedan guiar su trabajo. De allí que el afianzamiento también implica grados de confianza y de apegos que se vayan construyendo y dispensando mutuamente.

No obstante, las empleadas que solamente limpian deben hacer frente a una variedad de cuestiones. Si bien aquellas que lograron establecer una buena cantidad de casas están acostumbradas a diferentes lugares de trabajo, productos de limpieza diferentes y estilos diferentes de aseo, deben también manejar saberes específicos para cada hogar. Conocer las distintas "maneras de hacer" implica un trabajo desde el cual se movilizan distintos recursos para manejar mejor las distancias y las temporalidades con respecto a los requerimientos y exigencias de cada hogar. Así, Telma (42 años, separada, tres hijos, experiencia de veinte años en el servicio doméstico), menciona la relación entre el conocimiento de "lo que le gusta a cada patrona" y que "no te esté encima diciéndote, ¿vio esto que le dije, vio lo otro?”. Pero Telma manifiesta con claridad que para lograr que ello no ocurra el objetivo es poder conseguir que "la patrona te conozca, que sos alguien de bien, que trabajas bien, porque acá todo es así, hasta que te conocen sos el ogro". El carácter procesual de la confianza configura una base sin la cual las empleadas no pueden "trabajar tranquilas". La importancia que adquiere para este tipo de trabajos está al mismo tiempo relacionado con garantizar la elasticidad necesaria en sus itinerarios. En tal sentido, a continuación nos centramos en algunas técnicas particulares que desarrollan empleadas domésticas para lograr mejores condiciones de trabajo.

\subsubsection{Limpieza y pragmatismo}

En los hogares de Buenos Aires existen ciertos patrones comunes de limpieza donde se incluyen la limpieza de pisos, pasar la aspiradora, quitarle el polvo a los muebles y limpiar de manera minuciosa baño y cocina. En algunos casos, las empleadas discuten porque se les agregan tareas tales como lavado de ropa, planchado, cambio de sábanas y la limpieza del horno, de la heladera y de los vidrios, algo que puede ir a contramano de sus agendas laborales. Algunas empleadas no reconocen como parte del trabajo la limpieza de garajes, la limpieza de patios o de muebles, como tampoco sacar a pasear o bañar a los animales de la casa. "Hacer los vidrios", actividad que lleva tiempo, esfuerzo y hasta cierto riesgo físico en algunas ocasiones, es raramente requerida aunque en algunos casos realizada. Ante esta heterogeneidad de criterios y prioridades, 
encontramos que las empleadas deben manejar creativamente todas estas actividades para responder a los requerimientos de los empleadores y a sus propias agendas semanales. Además de la importante exigencia física que implica largas jornadas de trabajo, recorridos más o menos largos, a veces pasando por cuatro hogares en un mismo día, la realización de tareas "pesadas" de limpieza puede jugar en contra y generar situaciones de tensión con los empleadores.

Las empleadas que realizan únicamente tareas de limpieza reconocen que para lograr continuidad laboral en un hogar es necesario tener un gran cuidado en la utilización de productos y herramientas así como de ciertos gestos y actitudes que en algunos hogares pueden resultar propicios mientras que en otros pueden llegar a disgustarse por la utilización de modos similares. Así, por ejemplo, limpiar el horno con cierto producto y no con otro, secar tal mueble o pasar el trapo con mucha lavandina y de cierta manera, pueden ser prácticas requeridas en una en una casa, pero no en otra.

Un caso significativo en este sentido lo constituye Ester ${ }^{21}$ cuando sintetiza su perspectiva respecto a la relación que establece hace veinticuatro años con distintas empleadoras: "todas [las empleadoras mujeres] quieren algo distinto, aunque siempre lo más importante es la confianza que le das, tenés que conocerlas y saber lo que quieren (...) Las dos cosas llevan su tiempo". Al igual que muchas otras, Ester pudo cumplir de alguna manera con el "sueño" de muchas otras empleadas: lograr la confianza necesaria con sus empleadores para trabajar sola, tener las llaves de las casas y manejarse por intermedio de mensajes y notas escritas como el medio principal para comunicar pedidos, reclamos y sugerencias.

Ester admite que cuando empezó a trabajar tuvo que soportar "esas que te están relojeando todo el día", aunque algunas prácticas que interpuso cuando comenzó a charlar con sus amigas sobre el tema la llevaron a poder lograr mayor autonomía:

Yo a veces les he dicho, 'mire, que a mí no me gusta molestarla cuando usted está haciendo cosas importantes para su trabajo y yo paso la aspiradora' (...) entonces me dice que no les importa, pero después, al tiempo, ya no se quedan o están en la cocina, como en una guarida y eso es mejor para trabajar para nosotras.

\footnotetext{
21 Tiene 49 años, dos hijas, está separada y trabaja desde que llegó de Santiago del Estero hace veinticuatro años como empleada doméstica. Luego de trabajar siete años bajo la modalidad "sin retiro", pasó a trabajar para la misma familia "con retiro" durante cinco veces por semana para luego que sus hijas de 11 y 10 años comenzaron a concurrir al colegio primario, ella decidió empezar a trabajar "por horas".
} 
Manifestar estas dificultades por no ser entrometidas en las vidas de los empleadores muchas veces ha servido para lograr el objetivo de poder trabajar solas o con la menor intromisión posible. Ester agrega un nuevo elemento cuando reflexiona acerca de sus comienzos y manifiesta cómo, sobre todo en sus primeros momentos como empleada, la presencia de los empleadores cuando ella estaba realizando las tareas requeridas la habían puesto nerviosa en relación con la forma en que estaba haciendo su trabajo: "Es que muchos patrones la verdad que piensan que no sabes nada, entonces le tenés que mostrar lo que sabes". En tal sentido, la primera etapa, mayormente ligada al reconocimiento de saberes y estilos particulares de cada hogar, es siempre una etapa donde proliferan las tensiones y conflictos ligados a expectativas disímiles y maneras de interpretar y de gestionar el trabajo. Así, Ester argumenta desde una metáfora que aparece cotidianamente desde la perspectiva de las empleadoras:

(...) y...te lleva tiempo conocerte, yo siempre digo que es como una pareja, bueno, acá es lo mismo, entender las cosas como le gustan que se las hagan", porque "para decirte la verdad, vos estás entrando en su casa, en sus cosas, en su familia, qué sé yo, somos diferentes.

Una vez que esta etapa se supera y se logra la confianza adecuada, Ester menciona que "ya es una casa ganada" que solamente "hay que mantener, siempre haciendo lo que ellos quieren [y] les gusta, pero vos estás ya tranquila". Uno de los efectos positivos que tiene para ella haber podido establecer relaciones de larga data con sus empleadores es poder tener actualmente la libertad de manejar los tiempos y tareas en función de su propio itinerario de casas:

Así, por ejemplo, un lunes no llegué a planchar todo y ella sabe que yo lo hago en la semana, o si no puedo venir y de las ocho horas puedo hacer seis esa semana, después recupero dos horas. Es lo mejor cuando ya te tienen esa seguridad, porque vos te arreglas sola.

Tanto en el caso de Ester como en varias de las empleadas que trabajan "con retiro", encontramos una importante resistencia para aceptar trabajos en donde el tiempo es estrictamente supervisado. Ellas reciben de manera positiva aquellas instrucciones y orientaciones iniciales de los empleadores, y prefieren realizar sus tareas con la menor intromisión posible por parte de éstos. La presencia de empleadores mientras realizan el trabajo puede traer consecuencias negativas como son que se le agreguen más tareas, controle los ritmos de trabajo y la manera de limpiar y los métodos utilizados para hacer 
la limpieza, así como puede dificultar o atrasar la circulación que necesitan para moverse de un trabajo a otro.

Empleadas más experimentadas como Graciela (cuarenta y nueve años, una hija, separada, veinticinco años como empleada doméstica) reconoce que algunos empleadores se fijan todo el tiempo en el horario de entrada y de salida, observando las tareas que ellas realizan para poder obtener mayor cantidad de trabajo en menos tiempo, aunque sin darles ninguna compensación. A este tipo de empleador lo define como "hinchapelota", retratándolo de la siguiente manera:

Son esos que te persiguen, están ahí pensando qué más te pueden pedir, porque piensan que si no vos le estás robando, que no estás haciendo nada en las horas de trabajo (...) 'Haga esto, después el patio, no se olvide de pasarle el trapo a la parte de debajo de las patas de la mesa, no se olvide del garaje y de barrer el patio a fondo', ¡ésas son las peores!(...) ¡iel tema es que creen que sos un robot!!.

Cuando le pido a Graciela que defina cuál sería tu empleador/a ideal, su clasificación resulta precisa:

\begin{abstract}
Uno que le/me diga, 'mirá tenés que hacer esto, ésta es la llave', y que no esté atrás tuyo viendo cómo lo haces, vigilándote a cada instante. (...) Uno trabaja mejor cuando está solo, porque ya sabe trabajar, usted se toma el tiempo, puede escuchar música, cantar [risas], con algunas patronas la verdad que es muy lindo porque te dan esa libertad.
\end{abstract}

El orgullo y la satisfacción por hacer bien el trabajo se vinculan en muchos casos con la posibilidad de lograr autonomía en el mismo, y con que se puedan tornar visibles los resultados de sus esfuerzos. Tanto concebir como ejecutar y poder visualizar los resultados del trabajo son tres momentos que se unifican en este tipo de actividad. El último momento, instante que puede implicar aunque sea una última "mirada" a la labor realizada, constituye una instancia de gran relevancia para la empleada. Ese momento de satisfacción en el que la propia empleada puede controlar el resultado de su trabajo sólo puede darse cuando quienes limpian logran controlar la rutina de sus trabajos.

Finalmente, dentro de este grupo de empleadas que realizan únicamente tareas de limpieza pudimos encontrar un menor involucramiento afectivo con las familias donde trabajan $^{22}$ que aquellas empleadas que realizan tareas también de cuidado. Al mismo tiempo, trabajan con mayor autonomía y un mayor aislamiento del empleador, algo que

\footnotetext{
${ }^{22}$ A grandes rasgos esto es así, salvo en casos en los que la empleada termina trabajando "con retiro" después de hacerlo varios años - bajo la modalidad "sin retiro"- para los mismos empleadores. En estos casos encontramos desarrollada una implicancia afectiva mayormente con los menores de edad de la familia que lleva a un mayor compromiso con las personas y los objetos de ese espacio.
} 
es valorado por muchas de estas empleadas. Asimismo, y por la flexibilidad y diversidad de casas, las empleadas deben conocer y manejar criterios y reglas diferentes en muchos casos.

\section{Consideraciones finales}

A través de este artículo hemos podido evidenciar cómo las negociaciones, acuerdos y conflictos entre empleadoras y empleadas domésticas guardan una importante variabilidad y complejidad en función de la presencia o ausencia de las primeras y de la modalidad de trabajo y del tipo de tareas efectuado por las segundas. Asimismo, hemos visto cómo operan los propios mandatos morales y las posibilidades de acción que las empleadoras movilizan para gestionar y ejercitar la autoridad ante situaciones de conflicto y de tensión que se relacionan con la supervisión y control de las tareas domésticas.

En términos generales, la presencia y/o ausencia de las empleadoras ocupa un rol incide en la capacidad que tengan para supervisar, controlar y organizar la realización de tareas asignadas. Es así como aquellas que están menos en sus hogares tienen mayores dificultades para exponer sus criterios y expectativas debido a las dificultades que avizoran por una posible partida de la empleada, algo que se traduce en una dificultad para continuar con sus carreras profesionales. Esto deriva en muchos casos en una mayor autonomía de las empleadas tanto para aplicar y poner en práctica sus propios criterios de limpieza y de aplicar sus propias nociones de organización del hogar así como para manejar sus propias agendas laborales de entrada y salida de esos hogares.

Como hemos visto, estas empleadoras afirman preferir empleadas "con empuje" y capacidad de "adelantarse" ante situaciones y cuestiones que se pudieran presentar en la cotidianeidad $^{23}$. En tal sentido, buscan empleadas que les aseguren eficacia y responsabilidad en el trabajo. Sin embargo, la paradoja que se les presenta refiere a que si por un lado para estas empleadoras las labores domésticas y de cuidado constituyen tareas conocidas por cualquier mujer, por el otro, postulan la necesidad de hacer

\footnotetext{
${ }^{23}$ En otro trabajo (Canevaro, 2008) pude mostrar cómo y si bien esta imagen "profesionalizada" de la empleada aparece para las empleadoras como un anhelo que vuelva posible continuar con sus carreras profesionales y trabajos, a diferencia de lo que plantea Hondagneu Sotelo (2001), las empleadoras que trabajan no aparecen desinteresadas en mantener relaciones personales con las empleadas, sino que desde sus posibilidades se muestran interesadas en sus vidas y experiencias.
} 
comprensibles ciertos criterios de limpieza y de organización doméstica que reconocen como alejados de los propios saberes de las empleadas. En definitiva, y a pesar de sus cargados itinerarios laborales, ello no impide que aparezcan reproches y críticas sobre la forma en que se debe realizar el trabajo. Quizás, y a diferencia de quienes están más tiempo en sus hogares, entre estas empleadoras está menos presente la posibilidad de supervisión de aquellas "maneras de hacer" las tareas domésticas, con lo que el resultado termina siendo lo más importante. Al mismo tiempo, encontramos una cierta identificación en tanto "trabajadoras" que se actualiza a la hora de evidenciar sus requerimientos y pedidos y una mayor incomodidad para colocarse en la condición de "patronas". 24

Por su parte, quienes están más en sus hogares cuentan con mayor disponibilidad para frecuentar el hogar mientras la empleada se encuentra trabajando. Al mismo tiempo, en relación con el rol que ocupan dentro del hogar y con respecto a la familia, son estas empleadoras quienes mayormente manejan aquella "militancia moral" de las ideas higiénicas que las exhorta a practicar una supervisión del trabajo que realizan las empleadas que contratan. La supervisión y el control sobre las tareas realizadas -así como sobre la dinámica temporal del trabajo, las prioridades y la organización espacial del trabajo- ayudan a configurar una relación de mayor control y poder sobre la empleada. En tal sentido, estas empleadoras consideran necesario tratar de mantener ciertos axiomas y criterios básicos acerca de la limpieza, la higiene, el cuidado, la decoración, entre otras cuestiones. Así, se vuelve esencial que las empleadas sepan respetar sus indicaciones y observaciones que guardan sus propias exactitudes y especificidades. Por este motivo, cuando advierten que no pueden manejar a las empleadas por haber logrado éstas cierta independencia de criterio y acción, se producen situaciones donde la presencia de la empleada se vuelve una amenaza y un desafío en la construcción de su identidad como "patrona". En este sentido, la capacidad de poder brindar el ejemplo de manera directa le otorga cierto derecho y legitimidad para controlar y hacer respetar su propio estilo o "manera de hacer" que se presenta como la correcta dentro de cada hogar. Asimismo, entre estas empleadoras se encontró una mayor importancia otorgada a la gestión y el manejo del personal doméstico, siendo

\footnotetext{
${ }^{24}$ En otro trabajo pude explayarme y establecer una diferencia analítica entre aquellas empleadoras que en tanto trabajadoras tendían a tener una mayor sensibilidad e identificación con las empleadas, a quienes califiqué como "culposas"; mientras que otro grupo de empleadoras - que califiqué como "jerárquicas" tendían a tener opiniones y percepciones en donde los miedos y la poca afinidad con las trayectorias y experiencias de las empleadas resultaban notorias (Canevaro, 2008).
} 
la cuestión de los conflictos y las tensiones con éstas un tema recurrente en charlas y conversaciones.

En el caso de las empleadas, observamos la relevancia que la modalidad de trabajo articulado con el tipo de tarea a realizar adopta en la forma en que se organizan, gestionan y negocian las cuestiones laborales ligadas a las tareas de limpieza y de cuidado de los niños. Al mismo tiempo, se ha exhibido cómo el margen de negociación y la capacidad para poder desarrollar tácticas y maniobras que las puedan beneficiar en términos de las condiciones laborales ligadas con la cantidad de trabajo, los horarios de ingreso y de salida y el trato que puedan tener con las empleadoras y sus familias, se vinculan también con los grados de implicancia afectiva que logran establecer con los niños que cuidan.

En este sentido, se pudo vislumbrar que las empleadas "sin retiro" encuentran dificultades sobre el manejo del tiempo de trabajo y de descanso y emprenden maniobras para poder regularlo. Este manejo se vuelve complejo en tanto que la presencia es constante y la posibilidad de lograr espacios y temporalidades "libres" de trabajo resultan poco probables. Asimismo, y como ocurre en la mayoría de los casos, estas empleadas realizan tareas dedicadas a la limpieza al mismo tiempo que realizan tareas como niñeras. Así, deben lidiar en muchos casos no sólo con restringir la cantidad de horas de trabajo sino que también deben poder manejar los lazos emocionales y situaciones críticas que pueden sobrevenir en cada familia. Esta misma capacidad para manejar las "distancias afectivas" funciona para los empleadores tanto como una manera de negociar ciertos márgenes de autonomía y autoridad que le otorgan o restringe a las empleadas y niños por ejemplo, como una forma de aplacar ciertas disputas o generar acuerdos que les permiten examinar el trabajo de las empleadas.

En tal sentido, la afectividad aparece en este tipo de trabajos como una variable que regula derechos y deberes de ambas partes. Así, vimos cómo los reclamos pueden realizarse en clave afectivizante (“desconsideradas", "malas personas") pueden tornarse en estrategias tendientes a liberar a las empleadas de tener que realizar trabajos extra. Este "ser parte de la familia" o "como de la familia" puede llevar a que la disponibilidad se demuestre en el trabajo extra que la empleada llegue a realizar así como a soportar ciertas situaciones y condiciones de trabajo sin reconocimiento económico alguno.

En el caso de las empleadas "con retiro" que realizan únicamente tareas de limpieza, el envolvimiento afectivo es mucho menor que en las precedentes aunque ello no debe leerse como una ausencia de emociones y afectos envueltos. La construcción de 
los itinerarios para estas empleadas supone establecer buenas relaciones con las empleadoras ya que la flexibilidad que demandan sus obligaciones y las necesidades siempre cambiantes de las empleadoras hacen que sea necesario poder contar con un margen de maniobra para organizar sus recorridos. En general, estas empleadas logran tener una mayor flexibilidad de horarios y una estandarización de las tareas y de los tiempos que realizan. Éstas al mismo tiempo resisten la imposición de horas extras sino se compensa con pagos extras, algo que las ubica en una mejor posición. A diferencia de las empleadas "sin retiro", estas empleadas mencionan con bastante frecuencia la importancia que en ese trabajo tiene recibir instrucciones claras y precisas. En tal sentido, establecer horarios y tiempos precisos y fijos por parte de las empleadas que trabajan "sin retiro", así como tomar el control y buscar la mayor flexibilidad laboral y de horarios para las empleadas que trabajan "con retiro", constituyen tácticas que configuran y moldean la gestión de cada una de las modalidades de trabajo. Al mismo tiempo, encontramos que las empleadas "con retiro" manifiestan un mayor grado de conciencia respecto de las distancias culturales con sus empleadoras.

Asimismo, encontramos indicios en nuestros datos etnográficos en un tema que aparece poco explorado en los estudios que indagan en las interacciones entre empleadoras y empleadas, como son aquellas fronteras simbólicas y culturales que se actualizan desde las propias concepciones, prácticas y perspectivas sobre la higiene y el cuidado. En este punto, vislumbramos cómo lo doméstico, por tanto, se organiza en base a una idea de normalidad en donde la limpieza y un tipo de cuidado conforman una ética que, mediada desde patrones de la cultura dominante, busca crear sentimientos morales que lo legitimen. De esta manera, el arreglo de la casa de estas mujeres de sectores medios sigue un ideario higiénico que se apoya históricamente y que fácilmente puede ser desplazado hacia el campo de la moral. Este ordenamiento sigue una clasificación propia de las sociedades burocratizadas, donde las apreciaciones estéticas, de orden y de limpieza son reveladas desde una "administración del hogar" que desea optimizar espacios y tiempos.

Lo interesante, retomando a Brites (2001), emerge cuando en una sociedad en donde los mundos sociales jerárquicamente separados se pueden tocar diariamente, inclusive por la presencia de la empleada doméstica en los hogares burgueses, la casa burguesa, en tanto espacio "limpio" y "organizado", se vuelve una distinción en relación con el mundo de los pobres (Brites, 2001). Sin embargo, consideramos que tales patrones de domesticidad que se instauran como dominantes dentro de este espacio, no 
impiden que el universo cultural de las empleadas quede completamente sometido al poder que se instaura dentro del espacio doméstico. Creemos más bien en un proceso de creatividad simbólica por parte de los grupos populares que componen las empleadas domésticas, que, marcado por la diversidad de experiencias y prácticas aprendidas, logran trabajar y reelaborar tales patrones dentro de una lógica estipulada en la vivencia cotidiana de estos grupos. Se podría conjeturar que los desacuerdos que se evidencian en torno de la organización de lo doméstico entre empleadoras y empleadas componen algunos de los elementos significativos en la determinación de fronteras culturales entre estos grupos y en la constitución de diferentes universos simbólicos en las sociedades complejas, que resulta necesario seguir indagando en futuras investigaciones.

\section{Referencias}

ABAL MEDINA, Paula.2007 Notas sobre la noción de resistencia en Michel de Certeau. Revista KAIROS, Publicación de la Universidad Nacional de San Luis, Año 11, No 20.

BOURDIEU, Pierre y PASSERON, L. 1971. La Reproducción. Elementos para una teoría del sistema de enseñanza. Barcelona, Laia.

BRITES, Jurema. 2001. Afeto, Desigualdda e Rebeldia: bastidores do servico doméstico. Teses de Doutorado, Programa de Pos-Graduacao em Antropología Social, UFRGS, Porto Alegre.

CANEVARO, Santiago. 2008. Orden, desigualdad y afecto entre empleadoras del servicio doméstico en Buenos Aires. Trabajo presentado en el Congreso de Antropología Social, Universidad de Misiones, Argentina.

DE CERTEAU, Michel. [1979] 1996. La invención de lo cotidiano. El arte de hacer (1ed). México. Universidad Iberoamericana Editores.

1999. "De las prácticas cotidianas de oposición”, en Paloma Blanco (ed.) Modos de hacer: arte crítico, esfera pública y acción directa. España, Ed. Universidad de Salamanca.

DE LAS CASAS, Gloria y DE LAS CASAS, Mercedes. 2007. Como conseguir una mucama y no perderla en siete días. Buenos Aires, Editorial Planeta.

DUARTE, Luis Fernando Dias. 1986. Da vida nervosa das classes trabalhadoras urbanas. Río de Janeiro, Zahar.

FONSECA, Claudia. 1995. Caminos de Adopción. Buenos Aires EUDEBA.

GRIGNON, Claude y PASSERON, J.C. 1991. Lo Culto y lo Popular.Miserabilismo y populismo en sociología y literatura. Buenos Aires Nueva Visión.

HALL, Edward (1986). La dimensión oculta. México, Fondo de Cultura Económica. 
HONDAGNEU SOTELO, Pierrette. Doméstica. 2001. Inmigrant workers. Clearing and caring in the shadows of affluence. Berkeley, University of California Press.

Ministerio de Trabajo, Empleo y Seguridad Social. 2005. Subsecretaría de Programación Técnica y Estudios Laborales. Diagnóstico sobre la Situación Laboral de las Mujeres.

ROMERO, Mary. 1992. Made in the USA. New york. Routledge.

SCOTT, James.1985. Weapons of the Near. Everyday forms of peasant resistance. Newttavem: Yale University Press..

Recebido em: 17/07/2013

Aprovado em: 05/08/2013 